\title{
Desain Sistem Tata Kelola Dana Desa Berbasis Cloud Server
}

\author{
Algifanri Maulana*, Cosmas Eko Suharyanto \\ Universitas Putera Batam, Batam \\ *algifm@gmail.com
}

\begin{abstract}
This study aims to create a display of innovation systems in managing village funds by preparing vcloud computing-based innovations to manage all data generated so that local governments can help oversee the absorption of village budget funds in realtime and transparency. In this study researchers used qualitative methods because in this study focused on researching objects directly. This research is done by researching directly on innovation system of Batam City area. The research method by interview and observation from secondary data taken from the realization of village fund budget that has been running so as to produce data that can be controlled through cloud server based application. Stages performed in this design using desktop-based Visual studio applications which will be controlled via Client \& Server as a controller for processing and processing data. And for the database using postgresSQL database where later technology applications are made will be integrated via the Internet network. The results of this study is to provide a description of desktop system design as a reference to manage the village funds are transparent with the help of cloud server technology so that the data processed and processed can be monitored using the internet. It can also help the urban government to innovate village-based village fund governance governance so that funds that have been prepared and distributed can be controlled quickly, effectively and targeted through technology applications.
\end{abstract}

Keywords: Cloud Server; Innovations; Technology Applications; Village Funds.

\begin{abstract}
Abstrak
Penelitian ini bertujuan untuk membuat sebuah tampilan sistem inovasi daerah dalam mengelola dana desa dengan mempersiapkan inovasi berbasis cloud computing untuk mengelola semua data yang dihasilkan sehingga pemerintah daerah dapat membantu mengawasi penyerapan anggaran dana desa secara realtime dan transparansi. Pada penelitian ini peneliti menggunakan metode kualitatif karena dalam penelitian ini difokuskan pada meneliti obyek secara langsung. Penelitian ini dilakukan dengan meneliti secara langsung pada sistem inovasi daerah Kota Batam. Metode penelitian dilakukan dengan cara interview dan observasi dari data sekunder yang diambil dari realisasi anggaran dana desa yang sudah berjalan sehingga menghasilkan data yang dapat dikontrol melalui aplikasi berbasis server cloud. Tahap-tahap yang dilakukan dalam perancangan ini menggunakan aplikasi Visual studio berbasis desktop yang mana akan di kontrol melalui Client \& Server sebagai pengendali untuk pengolahan dan pemrosesan data. Dan untuk database menggunakan database postgresSQL. Di mana nanti teknologi aplikasi yang dibuat akan terintegrasi melalui jaringan internet. Hasil dari penelitian ini yaitu memberikan gambaran design sistem desktop sebagai acuan untuk mengatur dana desa yang transparan dengan bantuan teknologi cloud server sehingga data yang diproses dan diolah dapat di monitor menggunakan internet. Juga dapat membantu pemerintah kota Batam melakukan inovasi tata kelola dana desa berbasis teknologi informasi agar dana yang sudah disiapkan dan disalurkan dapat dikontrol dengan cepat, efektif, dan tepat sasaran melalui aplikasi teknologi.
\end{abstract}

Kata Kunci: Server Cloud; Inovasi; Teknologi Aplikasi; Dana Desa.

\section{Pendahuluan}

Dana Desa adalah dana yang bersumber dari Anggaran Pendapatan dan Belanja Negara yang diperuntukkan bagi desa yang ditransfer melalui Anggaran Pendapatan dan Belanja
Desa Kabupaten/Kota dan digunakan untuk membiayai penyelenggaraan pemerintahan, pelaksanaan pembangunan, Pembinaan kemasyarakatan, dan pemberdayaan masyarakat (Peraturan Pemerintah nomor 22 
tahun 2015). Menurut Prasetyanto dalam Prambudi (2014), pengawasan dana desa dilakukan oleh masyarakat melalui Badan Permusyawaratan Desa dan pemerintahan di atasnya, yaitu pemerintahan kabupaten/kota. BPD mempunyai peran yang sangat strategis dalam pengawalan pengelolaan dana desa agar tidak disalahgunakan atau diselewengkan sehingga dapat berjalan sebagaimana mestinya. Pemerintah Kota Batam berkomitmen menyiapkan anggaran $\mathrm{Rp} 1$ Milliar setiap Kelurahan mulai tahun 2017 yang digunakan untuk pembangunan infrastruktur demi meningkatkan kesejahteraan masyarakat. Program Rp 1 Milliar setiap kelurahan ini juga menyelaraskan program dari Pemerintahan Pusat dimana anggaran diambil dari APBD Kota Batam dikarenakan Kota Batam tidak mendapatkan bantuan dana desa dari pemerintahan pusat, maka pemerintah kota sendiri mengadakannya mengingat desa setara dengan kelurahan. Kenyataannya dalam penyelenggaraan pengelolaan dana masih belum optimal secara teknis dalam hal tata kelola untuk menghindari peluang penyalahgunaan dana yang telah didapat oleh masing - masing kelurahan. Selain itu diperlukan juga mekanisme kontrol dari masyarakat agar dapat dipergunakan tepat sasaran yaitu untuk meningkatkan kesejahteraan rakyat.

\subsection{Rumusan masalah}

Adapun rumusan masalah dalam penelitian ini yaitu: (1) Bagaimana design sistem tata kelola dana desa berbasis cloud server? (2) Bagaimana sistem kontrol persediaan yang dilakukan setiap desa dari dana yang sudah terpakai?

\subsection{Tujuan Penelitian}

Tujuan dari penelitan ini adalah sebagai berikut: (1) Untuk membuat sebuah tampilan design sistem dalam mengelola dana desa dengan mempersiapkan inovasi berbasis cloud; (2) Untuk mengelola semua data yang dihasilkan sehingga pemerintah daerah dapat membantu mengawasi penyerapan anggaran dana desa secara realtime dan transparansi.

\section{Kajian Literatur}

\subsection{Pengertian Keuangan Desa}

Keuangan Desa menurut UU Desa adalah semua hak dan kewajiban desa yang dapat dinilai dengan uang serta segala sesuatu berupa uang dan barang yang berhubungan dengan pelaksanaan hak dan kewajiban Desa. Hak dan kewajiban tersebut menimbulkan pendapatan, belanja, pembiayaan yang perlu diatur dalam pengelolaan keuangan desa yang baik. Siklus pengelolaan keuangan desa meliputi perencanaan, pelaksanaan, penatausahaan, pelaporan, dan pertanggungjawaban, dengan periodisasi 1 (satu) tahun anggaran, terhitung mulai tanggal 1 Januari sampai dengan 31 Desember (BPKP, 2015).

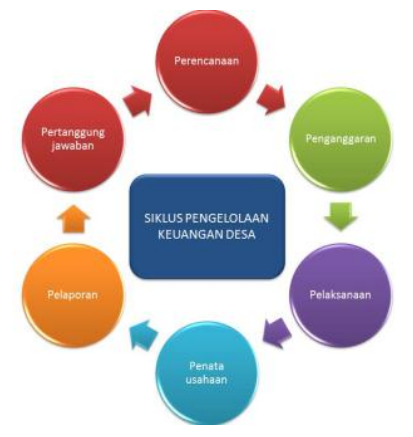

Gambar 1. Siklus Keuangan Desa

\subsection{Pengertian Cloud Server}

Cloud Server merupakan sebuah model untuk memberikan kenyamanan, pada akses jaringan permintaan beberapa pengguna untuk berbagi sumberdaya komputasi yang dikonfigurasi (misalnya, jaringan,server, penyimpanan, aplikasi, dan jasa) yang dapat dengan cepat ditetapkan dan dirilis dengan usaha pengelolaan yang minimal atau interaksi penyedia layanan. Menurut Mulyani juga memberikan definisi bahwa cloud server pada dasarnya adalah penggunaan Internet-based service untuk mendukung proses bisnis. Cloud server memberikan suatu solusi terhadap permasalahan mengenai kebutuhan teknologi informasi ( $\mathrm{TI})$ saat ini, baik untuk individu, perusahaan swasta maupun organisasi pemerintahan.

\subsection{Penelitian Terdahulu}

Penelitian terdahulu dari penelitian ini yaitu diantaranya: (1) Akuntabilitas Pengelolaan Dana Desa ( Studi Kasus Pengelolaan Alokasi Dana Desa di Desa-Desa Dalam Wilayah Kecamatan Tlogomulyo Kabupaten Temanggung Tahun 2008) oleh Agus Subroto, Hasil penelitian ini menunjukkan bahwa untuk perencanaan dan pelaksanaan kegiatan Alokasi Dana Desa, sudah menampakkan adanya pengelolaan yang akuntabel dan transparan. Sedangkan dalam pertanggungjawaban dilihat secara hasil fisik sudah menunjukkan pelaksanaan yang akuntabel dan transparan, namun dari sisi administrasi masih diperlukan adanya pembinaan lebih lanjut, karena belum sepenuhnya sesuai dengan ketentuan. Kendala. (2) Sistem Informasi Pengelolaan Keuangan Pada Desa Ngadirejan oleh Atik Rusmayanti, memberikan gambaran bahwa sistem keuangan masih menggunakan metode konvensional dimana seluruh catatan 
keuangan di kelola dari satu buku saja, dari catatan manual sehingga dijadikan sebuah sistem informasi guna mempermudah pihak kantor desa dalam proses pengelolaan keuangan dan juga membantu dalam proses penginputan data, pencarian data, dan laporan data keuangan.

\section{Metode Penelitian}

Metode penelitian dilakukan dengan cara interview dan observasi dari data sekunder yang diambil dari realisasi anggaran dana desa yang sudah berjalan sehingga menghasilkan data yang dapat dikontrol melalui aplikasi berbasis cloud server. Tahap-tahap yang dilakukan dalam perancangan ini menggunakan aplikasi Visual studio berbasis desktop yang mana akan di control melalui Client \& Server sebagai pengendali untuk pengolahan dan pemprosesan data. Dan untuk database menggunakan database postgres SQL dimana nanti teknologi aplikasi yang dibuat akan terintegrasi melalui jaringan internet. Hasil dari penelitian ini yaitu memberikan gambaran design sistem desktop sebagai acuan untuk mengatur dana desa yang transparan dengan bantuan teknologi cloud server sehingga data yang diproses dan diolah dapat di monitor menggunakan internet.

\section{Hasil dan Pembahasan}

\subsection{Tahapan Perencaan Penganggaran}

Tahapan awal perncanaan penganggaran yang dilakukan berdasarkan aturan dari pemerintah pusat dalam mengatur dan mendapatkan anggaran dana desa.

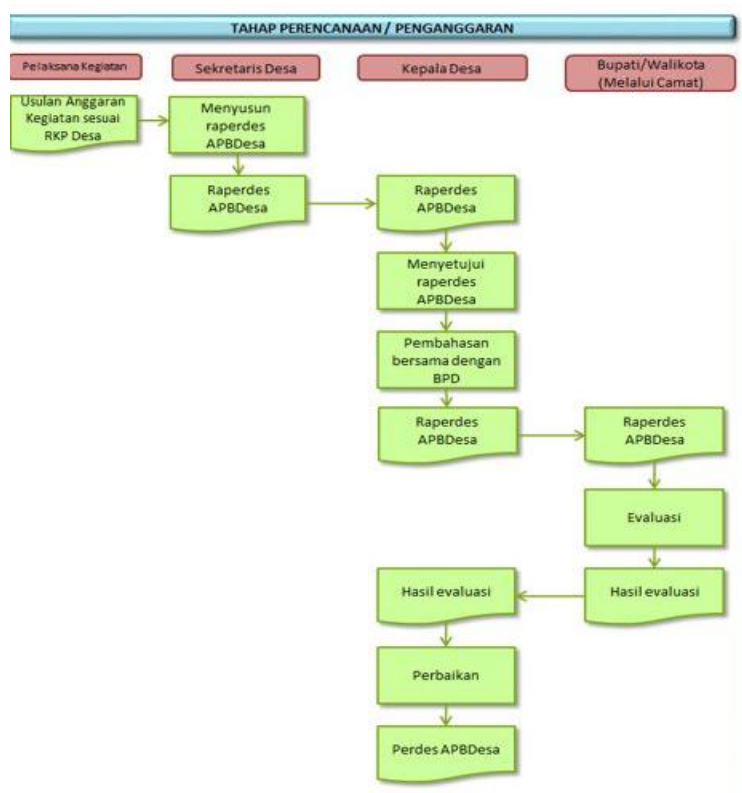

Gambar 2. Flowchart penyusunan APB Desa

Anggaran Pendapatan dan Belanja Desa (APB Desa) merupakan rencana anggaran keuangan tahunan pemerintah desa yang ditetapkan untuk menyelenggarakan program dan kegiatan yang menjadi kewenangan desa. Proses Penyusunan APB Desa dimulai dengan urutan sebagai berikut: (1) Pelaksana Kegiatan menyampaian usulan anggaran kegiatan kepada Sekretaris Desa berdasarkan RKP Desa yang telah ditetapkan; (2) Sekretaris Desa menyusun rancangan Peraturan Desa tentang APB Desa (RAPB Desa) dan menyampaikan kepada Kepala Desa; (3) Kepala Desa selanjutnya menyampaikan kepada Badan Permusyawaratan Desa untuk dibahas dan disepakati bersama. Rancangan Peraturan Desa tentang APB Desa disepakati bersama paling lambat bulan Oktober tahun berjalan antara Kepala Desa dan BPD; (4) Rancangan Peraturan Desa tentang APB Desa yang telah disepakati bersama sebagaimana selanjutnya disampaikan oleh Kepala Desa kepada Bupati/Walikota melalui camat atau sebutan lain paling lambat 3 (tiga) hari sejak disepakati untuk dievaluasi; (5) Bupati/Walikota menetapkan hasil evaluasi Rancangan APB Desa paling lama 20 (dua puluh) hari kerja sejak diterimanya Rancangan Peraturan Desa tentang APB Desa. Dalam hal Bupati/Walikota tidak memberikan hasil evaluasi dalam batas waktu maka Peraturan Desa tersebut berlaku dengan sendirinya. Dalam hal Bupati/Walikota menyatakan hasil evaluasi Rancangan Peraturan Desa tentang APB Desa tidak sesuai dengan kepentingan umum dan peraturan perundang-undangan yang lebih tinggi Kepala Desa melakukan penyempurnaan paling lama 7 (tujuh) hari kerja terhitung sejak diterimanya hasil evaluasi. Apabila hasil evaluasi tidak ditindaklanjuti oleh Kepala Desa dan Kepala Desa tetap menetapkan Rancangan Peraturan Desa tentang APB Desa menjadi Peraturan Desa, Bupati/Walikota membatalkan Peraturan Desa dengan Keputusan Bupati/Walikota yang sekaligus menyatakan berlakunya pagu APB Desa tahun anggaran sebelumnya; (6) Peraturan Desa tentang APB Desa ditetapkan paling lambat tanggal 31 Desember tahun anggaran berjalan.

\subsection{Tahapan Perancangan Sistem}

Berikut tahapan dalam desain yang akan diterapkan dalam sistem untuk mengelola persediaan dana desa: 


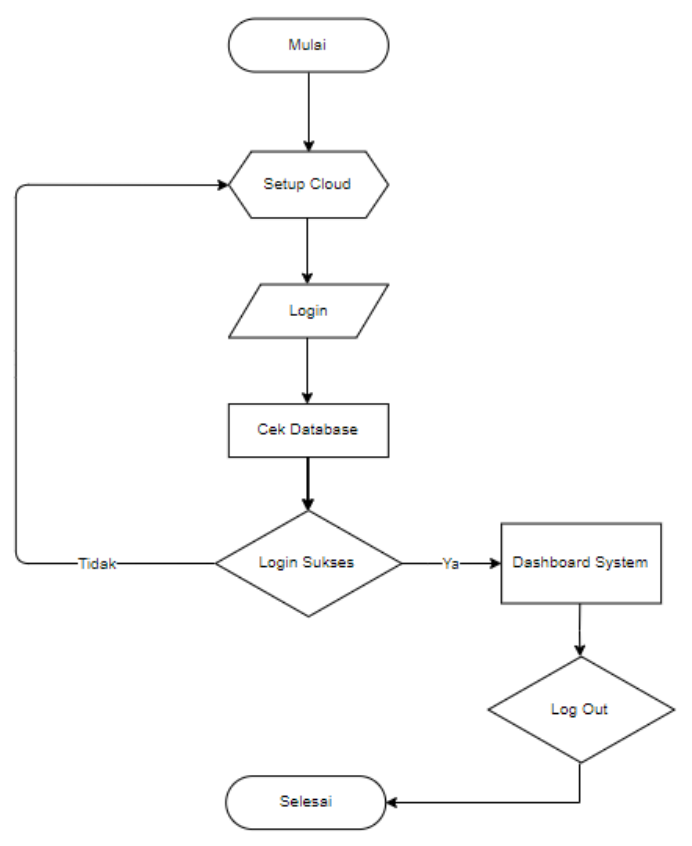

Gambar 2. Flowchart Desain Sistem

Dalam perancangannya perlu dilakukan setup server di cloud third party terlebih dahulu untuk memindahkan database local ke cloud server. Server yang digunakan yaitu dari Digital Ocean dengan spesifikasi Ubuntu 12.0. Desain yang dirancang untuk membangun sistem tata kelola dana desa yakni sebagai berikut:

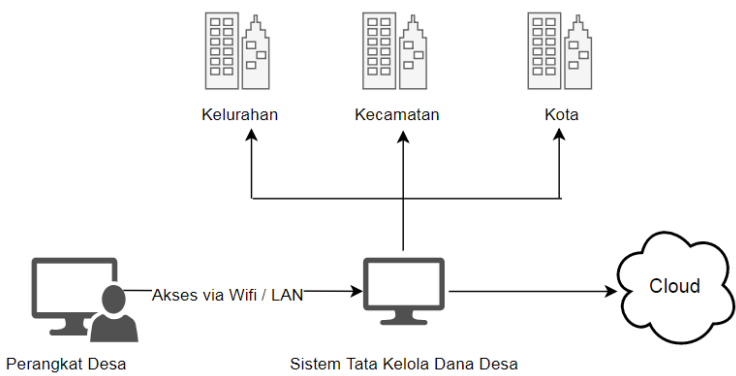

Gambar 4. Arsitektur Sistem

Arsitektur sistem yang dirancang bahwa segala bentuk aktifitas sistem dapat diakses melalui jaringan internet baik itu menggunakan jaringan wifi maupun LAN connection. Hal ini dapat memudahkan semua stakeholder perangkat desa bisa mengakses dari mana pun selama ada koneksi internet.

\subsection{Design ERD Sistem Cloud}

Untuk mendukung design sistem tata kelola dana desa berikut ini adalah ERD pada sistem tata kelola dana desa yang telah dirancang untuk mempresetasikan model data yang ada pada sistem:

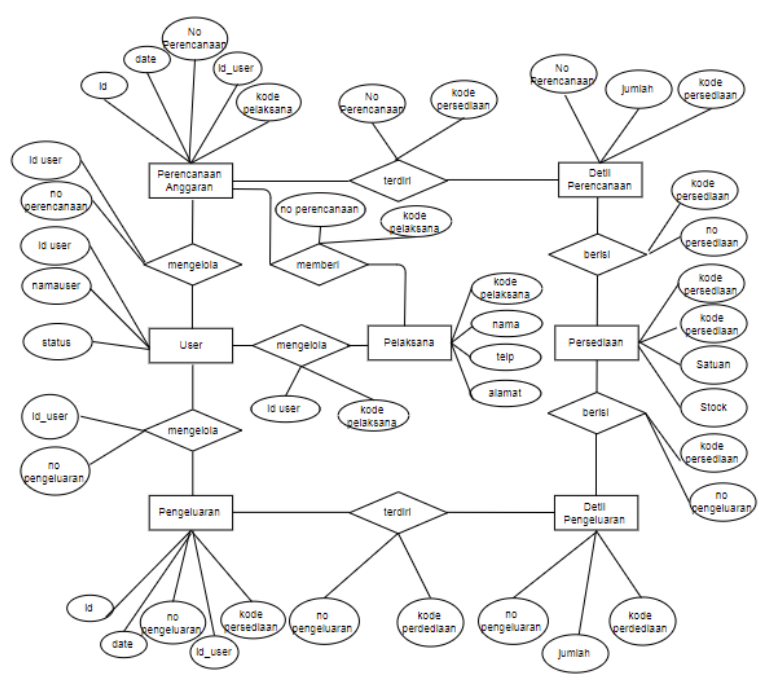

Gambar 5. ERD Desain Sistem

Ada empat bagian terpenting dalam perancangan sistem, diantaranya terdapat modul perencanaan anggaran, pengeluaran, pelaksanaan, dan juga modul persediaan. Dimana sistem fokus untuk memberikan informasi mengenai persediaan dan kontrol stock dana desa yang telah digunakan. Selain itu juga database yang dirancang sesuai dengan data manual yang didapatkan untuk dijadikan acuan dalam melakukan transaksi penyimpanan.

\subsection{Tampilan Desain Sistem}

Pada tahapan ini dibuat prototype desain interface untuk aplikasi yang nantinya akan digunakan Kantor Lurah. Rancangan tahapan tampilan pada saat ini terbatas pada perancangan antarmuka, dashboard system dan laporan - laporan persediaan. Berikut ini beberapa tampilan desain sistem:

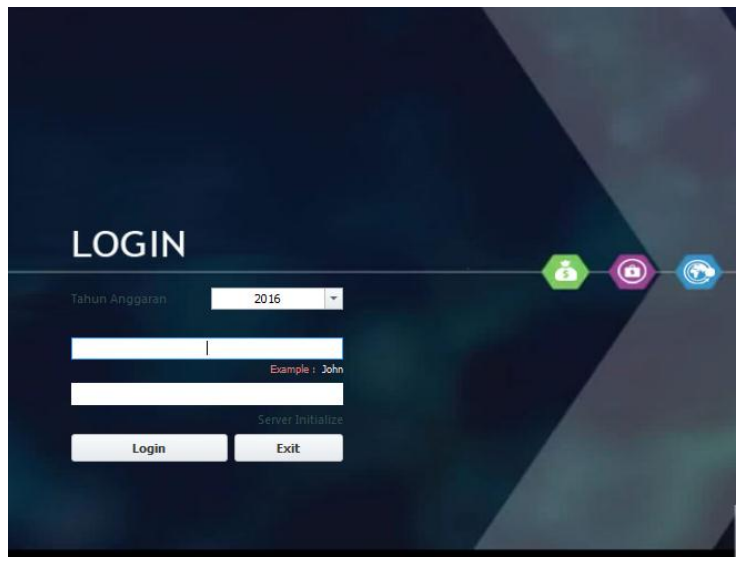

Gambar 6. Tampilan Login

Login form digunakan oleh user yang terdiri atas, staff kantor lurah, sekretaris, bendahara maupun kepala desa dimana pertama kali dimunculkan data untuk tahun anggaran berapa yang akan diproses dan diajukan. 


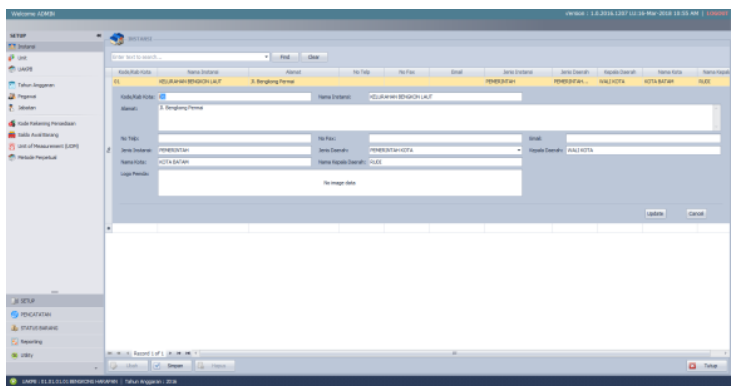

Gambar 7. Dashboard Setup

Modul setup ini digunakan pertama kali untuk setup nama instansi kota/kabupaten yang akan menggunakan sistem tata kelola dana desa berisi informasi terkait jenis instansi, jenis daerah, kepala daerah. Selain itu pada modul setup juga terdapat beberapa menu diantaranya yaitu: Unit, Tahun Anggaran, Pegawai, Jabatan, Kode Rekening Persediaan, saldo awal barang, metode perpetual. Untuk tahapan awal desain sistem ini fokus ke arah persediaan di satu unit desa. Pemaparan prototipe desain telah dilakukan bersama guna mendapatkan hasil desain sistem yang sesuai untuk mendukung kinerja kantor desa.

Selain modul setup ada juga beberapa modul lainnya pada desain sistem tata kelola dana desa diantaranya: modul pencatatan, modul status barang, modul reporting dan juga modul utility.

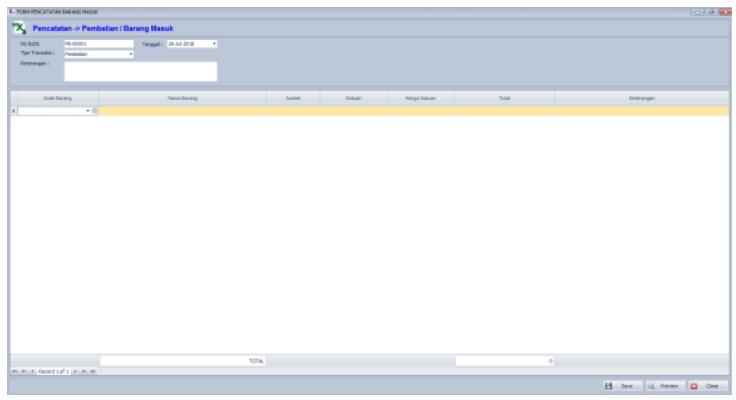

Gambar 8. Tampilan Pencatatan Barang Masuk

Menu ini berfungsi untuk kontrol setiap pembelian barang-barang masuk untuk penggunaan desa maupun daftar mutasi keluar.

\subsection{Perancangan Cloud Server}

Dalam tahapan prototipe perancangan ini peneliti mencoba menggunakan server dari Digital Ocean dengan spesifikasi Ubuntu 17.04 x64.

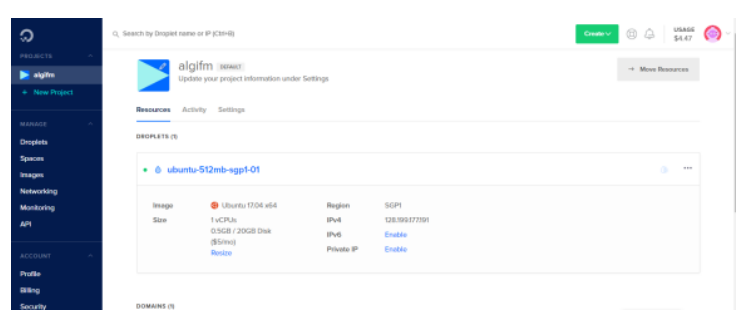

Gambar 9. Dashboard Digital Ocean

Digital ocean merupakan salah satu provider penyedia VPS dimana pihaknya menyiapkan sistem operasi resources sesuai dengan keinginan kita. Berikut langkah-langkah dalam pembelian server pada digital ocean: (1) Daftarkan akun dengan menggunakan email yang aktif; (2) Setelah registrasi, kita dapat memilih doplet yang akan kita instal dan digunakan untuk dijadikan server cloud kita. Silahkan sesuaikan dengan kebutuhan baik itu kapasistas, location server dan harga yang ditawarkan dari digital ocean. (3) Setelah proses selesai maka semua username dan password akan dikirimkan melalui email yang terdaftarkan, langkah selanjutnya adalah setup server yang sudah tersedia; (4) Install database postgresql pada server yang telah selesai di install.

\section{Kesimpulan dan Saran}

Adapun kesimpulan dari penelitian ini adalah (1) penerapan pada desain sistem tata kelola berbasis cloud server memudahkan semua pihak terkait untuk mengontrol seluruh transaksi secara realtime, (2) Sistem dapat dijalankan dengan menggunakan koneksi wifi maupun LAN. (3) Cloud server dapat menjadi sebagai pusat data dari masing-masing instansi Kelurahan, Kecamatan, Kabupaten/Kota.

Adapun saran dari penelitian ini adalah (1) Kembangngkan aplikasi untuk berbasis web dan mobile karena fitur teknologi kedepan akan terus berkembang seiring dengan berjalannya waktu, (2) Perlu dilakukan backup data secara berkala, karena sewaktu-waktu data yang ada pada cloud bisa saja hilang secara tiba-tiba, (3) Tambahkan modul untuk memberikan laporan langsung kepada masyarakat agar dana yang terpakai dan tersalurkan dapat diawasi secara bersama - sama.

\section{Ucapan Terima Kasih}

Ucapan terima kasih peneliti ucapkan kepada ristektdikti karena telah memberikan kesempatan kepada saya dalam penelitian dosen pemula, juga affiliasi peneliti Universitas Putera Batam yang selalu support dan memacu semangat untuk terus melakukan penelitian demi menghasilkan karya yang dapat berguna dan bermanfaat bagi masyarakat 


\section{SNISTEK (1) 2018}

\section{Daftar Pustaka}

Bharti, M., \& Bala, a. (2012). Workflow Management in Cloud Computing. Research.ljais.Org, 4(9). Retrieved from http://research.ijais.org/volume4/number9/ijais12 -450788.pdf

BPKP. (2015). Petunjuk Pelaksanaan Bimbingan dan konsultasi Pengelolaan Keuangan Desa. Deputi Bidang Pengawasan Penyelenggaraan Keuangan Daerah.

Czarnul, P. (2013). An evaluation engine for dynamic ranking of cloud providers. Informatica (Slovenia), 37(2), 123-130.

Danang Setiyawan Ahmad Ashari, S. A. S. (2014). Implementasi Cloud Computing Menggunakan Model Infrasrtucture as a Service Untuk Optimalisasi Data Center. Jurnal Dasi, 15(1), 1411-3201.

Desa, D., \& Desa, D. I. (n.d.). Sistem informasi pengelolaan alokasi dana desa di desa sukarami, (12), 1-6.

Hamdani, J., \& Wirawan, C. (2012). Open Innovation Implementation to Sustain Indonesian SMEs, 4(Icsmed), 223-233. https://doi.org/10.1016/S2212-5671(12)00337-1

Muhammad Ibrahim. (2013). Analisis Dan Implementasi Owncloud sebagai media penyimpanan pada Yayasan Salman Al-Farisi Yogyakarta Pendahuluan Landasan Teori Pembahasan. Analisis Sistem Penyimpanan Data Menggunakan Sistem Cloud Computing Studi Kasus SMK N 2 Karanganyar, 14(04), 32.

Riyanto, A. (2016). Keuangan Desa, (September), 71-78.

Rusmana. (2013). Sistem Informasi Pengelolaan Keuangan dana bantuan pada kecamatan Arjosari, 11(2), 43-46.

Rusmayanti, A., \& Purnama, B. E. (2010). Sistem Informasi Pengelolaan Keuangan. Indonesian Journal on Computer Science - Speed, 19799330, 1-5.

Winkenali, E. (2016). Desain Sistem Informasi Akuntansi Desa dalam Rangka Meningkatkan Transparansi dan Akuntabilitas Keuangan Desa Design of Accounting Information Systems in Village to Improve Transparency and Financial Accountability, (September), 391-397. 